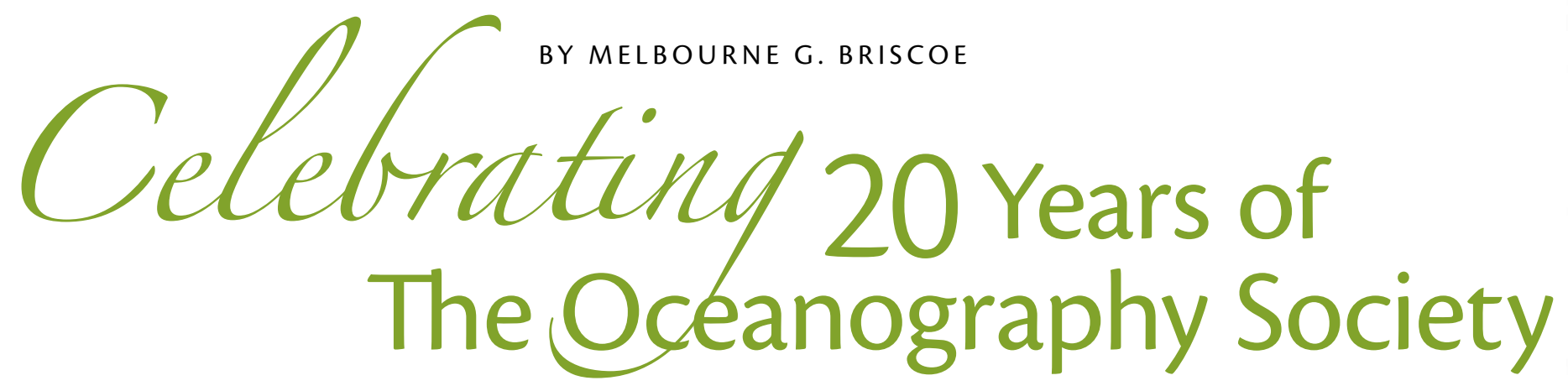

\title{
An Introduction to the Special Issue
}

The Challenger Expedition set sail on December 21, 1872, not quite a century and a half ago. Today we describe that expedition as the beginnings of our science. The introductory paragraph of the 1895 "Summary Report on the Scientific Results of the Voyage of the H.M.S. Challenger" points out that the deeper parts of the ocean had not been investigated because, "the apparatus necessary for such investigation had not yet been invented." The next paragraph reveals one of the motivations for the expedition: "The desire to establish telegraphic communication between Europe and America gave the first direct impulse towards a systematic exploration of the deep sea." The third paragraph of the introduction, describing what oceanography encompassed in 1895, is worth quoting in its entirety:

The oceanographer takes account of everything relating to the ocean; his investigations deal with the form and divisions of all marine areas on the surface of the globe, the winds that blow over the surface waters, the contours of the ocean bed from the sea-level down to the greatest depths, the temperature, the circulation, the physical and chemical properties of sea-water, the currents, tides, waves, the composition and distribution of marine deposits, the nature and distribution of marine organisms at the surface, in the intermediate waters, and on the floor of the ocean, as well as the modifications brought about in living things by the conditions of their existence, the relations of man to the ocean in the development of fisheries, commerce, civilization, navigation, hydrography, and maritime meteorology. All this vast assemblage of knowledge, which embraces some aspects of astronomy, geography, geology, physics, chemistry, and the biological sciences, makes up the modern science of oceanography.

We can see in these quotations the beginnings of some of the founding principles of The Oceanography Society (TOS): good science can be driven by very practical needs, science depends on technological developments, and oceanography is inherently multidisciplinary.

Walter Munk's article in this issue of Oceanography begins with his work in 1944 on a very practical problem: wave predictions for the Allied landings that will occur in Normandy the following year. He describes other work at the same time on sound propagation in the ocean, essential to the detection of submarines and arguably central to the mitigation of the Soviet submarine threat several decades later. An underlying theme of his article is that good scientists can do science while working on very practical problems, and this effort can be rewarding, productive, and fun. He wonders at the end of his essay if this spirit is gone, can that "excitement and joy of the postwar period" ever be recovered? Perhaps we need to stand back and ask what has made it go away, before we ask if we can get it back.

Jim Baker and Stan Wilson revisit the reasons that TOS was started, and challenge us to keep thinking about and planning for the future so as not to be inundated by it. They point out that funding for ocean science was a motivational factor in 1987-1988 during the Society's formative years, but is now the overwhelming concern of many. One can wonder if the rise of funding issues is part of the demise of the excitement and joy mentioned by Munk.

Susan Kubany has been close to TOS from the start. She (and her late husband, Bob Heinmiller) attended the informal formative meeting of TOS in January 1988 and their firm, Omnet, 
contributed the logo that TOS uses to this day. Her essay is a combination of history, insight, and lament for the lost days of excitement and promise. Those of us who were part of the growth and passing of what-may-have-been-the best-communication-system-within-allthe-sciences share the lament, but thank the founders for their work and passion.

Larry Clark introduces a collage of short contributions on women in oceanography. Mentioned in several of the contributions is the different approach to oceanography that women seem naturally to take: more collaborative, more work by consensus, more focused on societal issues and education, and lifestyles more balanced between home and work. Marie Colton refers to the "complex cultural lessons learned by women as the ocean community moved from competition to global collaboration" as a goal for all of us in the future. This theme echoes throughout most of the special issue.

Tom Curtin and Ed Belcher provide a remarkable piece that analyzes four innovative technological developments that have changed-and continue to change-our ability to work in and describe the ocean: temperature-salinity profiling; acoustic communications; high-resolution, lens-based sonars; and ocean gliders. They point out that it may take decades for something to become an overnight success, that success is "tortuous" and not really predictable, that external factors such as developments in other fields may be the pacing elements, and that tenacity and vision are essential. Oceanography played a critical role in bringing gliders to our hands.

Tom Powell reviews the history of interdisciplinary work in the ocean sciences, how it was just coming in vogue a few decades ago, and why it is now essential, especially if one is working on real problems that have societal impact. He mentions Don Olson's 1988 article in Oceanography (Volume 1[2]) offers reasons why such collaboration is difficult; they include institutional barriers, funding sources, and narrowly focused training of students. Powell then comments: "It gives one pause to realize that in 20 years, our community has made only meager progress in tackling these problems." He ends his review, however, with the excitement of a true scientist, commenting: “...once the sketch of a phenomenon becomes available from initial observations, the drive for fuller understanding of the 'whole picture' becomes irresistible. Most likely, that fuller understanding may involve the insights from another discipline. Our curiosity gets the better of us."

In my (Mel Briscoe) contribution, I take the collaboration topic mentioned in many of the other articles and characterize it as the way we must work in the future to tackle the problems posed by society. Using information from studies of collaboration, I offer some best practices and common pitfalls as distilled aids for those ocean scientists entering into collaborative endeavors. If growing collaboration is the theme of many of the other articles, then this article is the handbook on how to proceed.

Ellen Prager describes her fantasy of a society in which people understand and are excited by ocean science. She argues that formal and especially informal education is a must, and that it is too important to be left to the few professionals who do it-we must all get involved. Her thesis, however, is that we do not communicate well to the public, and she is buttressed in this by some interesting contributions from media representatives. Perhaps we are our own worst enemy, because our rewards and kudos do not typically go to those who spend time talking to the public or the media.

Mark Abbott paints the future of 2028 as one in which funding will be even harder to get than it is today, and suggests some directions that ocean science might take to mitigate those pressures. He argues the future will have much more integration across many sciences, including those involving the human dimension; his view of interdisciplinary pressures mirrors or extends those of other authors in this special issue. Abbott takes on the necessity of change in our organizational structures to respond to these influences, and wonders if "peer review" is up to the task of judging the proposals of the future. He foresees major changes in universities, funding agencies, attitudes toward "applied" work, and the very existence of oceanography as a discipline; perhaps oceanography will become the topic on which people will work, rather than the discipline they have studied and are constrained by. Flexible collaborations are, again, a theme he raises.

I personally look forward to 2028 to celebrate TOS's fortieth anniversary, and to see if Mark is right. We thank the authors who have connected the past with the future in this volume. We have been challenged, we must respond, and we are up to it; TOS will help.

Melbourne G. Briscoe (Mel@Briscoe.com) is President, OceanGeeks, LLC, Alexandria, VA, USA, and founding secretary of The Oceanography Society. שd 